\title{
INTERNATIONAL COMPARISON OF X-RAY STANDARDS ${ }^{1}$
}

\author{
By Lauriston S. Taylor
}

ABSTRACT

Direct comparisons between the X-ray ionization standards of the United States, England, Germany, and France are described. The small guarded field ionization chamber was used as the working standard and transported to the several laboratories. Careful check of the instrument calibration at each laboratory showed no change due to transportation. Complete corrections were made for air absorption, differences in current measurements, and differences between chamber diaphragms. The final agreement between the standards of the United States, England, and Germany was \pm 0.5 per cent. The ratio between the International Röntgen and Solomon's Unit for hard radiation $(H . V$. L. greater than $0.75 \mathrm{~mm} \mathrm{Cu}$.) was 2.29. As a result of diaphragm discrepancies found in England, a study of diaphragm measurements was made. It was found that the lead diaphragms tended to warp with age rendering difficult and accurate determination of their area. Plug gage and micrometer microscope measurements were averaged for the final results.

\section{CONTENTS}

Prge

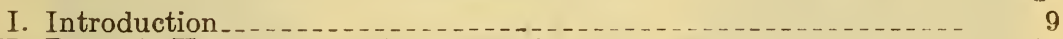

II. Portable X-ray standardization equipment_... 10

1. Description of apparatus 10

2. Accuracy of calibration 12

III. Comparisons in this country 12

IV. Comparison with National Physical Laboratory

V. Comparison with Physikalisch-Technische Reichsanstalt_....... 16

VI. Comparison with French standard

VII. Study of ionization chamber diaphragms 20

VIII. Conclusion-Joint recommendations of the Bureau of Standards, National Physical Laboratory, Physikalisch-Technische Reichsanstalt and le Service d'Etalonnage de l'Hôpital St. Antoine...-

\section{INTRODUCTION}

The unit of X-ray quantity known as the Röntgen has within the last few years become very generally used in applied radiology. In the meantime many investigators have studied the problem of devising an equipment which will unambiguously measure an X-ray beam according to the definition of the international Röntgen as proposed by the Second International Congress of Radiology in $1928^{2}$ and many important features overlooked by the earlier investigators have been brought out. ${ }^{3}$ There has at the same time been set up in the national laboratories of England, Germany, and the United States, standard open-air ionization chambers in terms of which dosage meters for the particular country are calibrated..$^{45}$

\footnotetext{
1 Preliminary report read by L. S. Taylor at Third International Congress of Radiology, Paris, July 29 1931.

2 The Röntgen is defined as "the quantity of $\mathrm{X}$ radiation which when the secondary electrons are fully utilized and the wall effect of the chamber is avoided, produces in 1 cubic centimeter of atmospheric ait at $0^{\circ} \mathrm{C}$. and $760 \mathrm{~cm}$ mercury pressure, such a degree of conductivity that one electrostatic unit of charge is measured at saturation current."

a See review paper by L. S. Taylor, Radiology, vol. 16, p. 1; 1931
}

$1 \mathrm{H}$. Behnken, Strahlentherapie, vol. 26, p. 79; 1927.

3 L. S. Taylor, B. S. Jour. Research, vol. 2 (RP56), p. 771; 1929

$6 \mathrm{G}$. W. C. Kaye and W. Binks, Brit. J. Rad., vol. 2, p. 553; 1929. 
Other countries, not having centralized standardization laboratories have designated certain private or State institutions as recognized custodians of the standard. In France Dr. I. Solomon at l'Hôpital St. Antoine is the official custodian.

Since the different national standards have been designed and constructed independently it is natural to find that no two are exactly alike, even though the basic principles involved in all are the same. On account of these differences the most obvious question was how closely these several standards agreed.

The first attempt at comparison was made in 1927 by Behnken. ${ }^{7}$ For this purpose he carried a pair of carefully controlled thimble chambers, which had been calibrated against his standard, to several laboratories for comparison. His results revealed a difference between several American laboratores (not including the Bureau of Standards, since we had no X-ray standardization equipment at that time) and the Physikalische-technischen Reichsanstalt of some \pm 4 per cent. More recent studies ${ }^{89}$ have shown that an unambiguous calibration is exceedingly difficult. Behnken's comparison measurements were made with a magnesium thimble chamber which, therefore, had a considerable dependence upon the radiation quality as compared with an open-air ionization chamber. The impossibility of reproducing the necessary radiation qualities in the different laboratories consequently influenced the accuracy of the measurements in an unfavorable way.

It appeared, therefore, that a direct comparison between the standards themselves would be the only reliable method..$^{10}$ This has heretofore been practically precluded by the very great weight and size of these open-air standards. The guarded field ionization chamber developed in this laboratory ${ }^{11}{ }^{12}$ appeared, however, to be sufficiently compact to transport, so the bureau arranged for a comparison with with the national laboratories of England and Germany; also with Doctor Solomon's laboratory of France.

\section{PORTABLE X-RAY STANDARDIZATION EQUIPMENT}

\section{DESCRIPTION OF APPARATUS}

The working standard used in these comparisons was a small guarded field ionization chamber previously described, ${ }^{11} 12$ though some minor modifications from that description were made to facilitate the more ready alignment in the $\mathrm{X}$-ray beam. At the same time, the beam was isolated from the guard wires by reducing their number from 12 to 8 , which permitted a spacing of $1.8 \mathrm{~cm}$. between the central pair. With the chamber diaphragm of only $0.8 \mathrm{~cm}$ diameter there was little likelihood of the beam striking the wires unless the chamber were placed abnormally close to the tube. The change in spacing of the guard wires necessitated, however, a $3 \mathrm{~cm}$ increase in the length of the surrounding box to maintain a uniform electric field between the collector plates. To insure ruggedness, the

7 H. Behnken, Strahlentherapie, vol. 29, p. 192; 1928.

8 L. S. Taylor and G. Singer, B. S. Jour. Research, vol. 4 (RP169), p. $631 ; 1930$.

- L. S. Taylor and G. Singer, Radiology, vol. 15, p. 227; 1930 .

10 L. S. Taylor, Radiology, vol. 14, p. 55i; 1930.

11 L. S. Taylor and G. Singer, B. S. Jour. Pesearch, vol. 5 (RP211), p. 507; 1930

12 L. S. Taylor and G. Singer, Radiology, vol. 15, p. 637; 1930. 


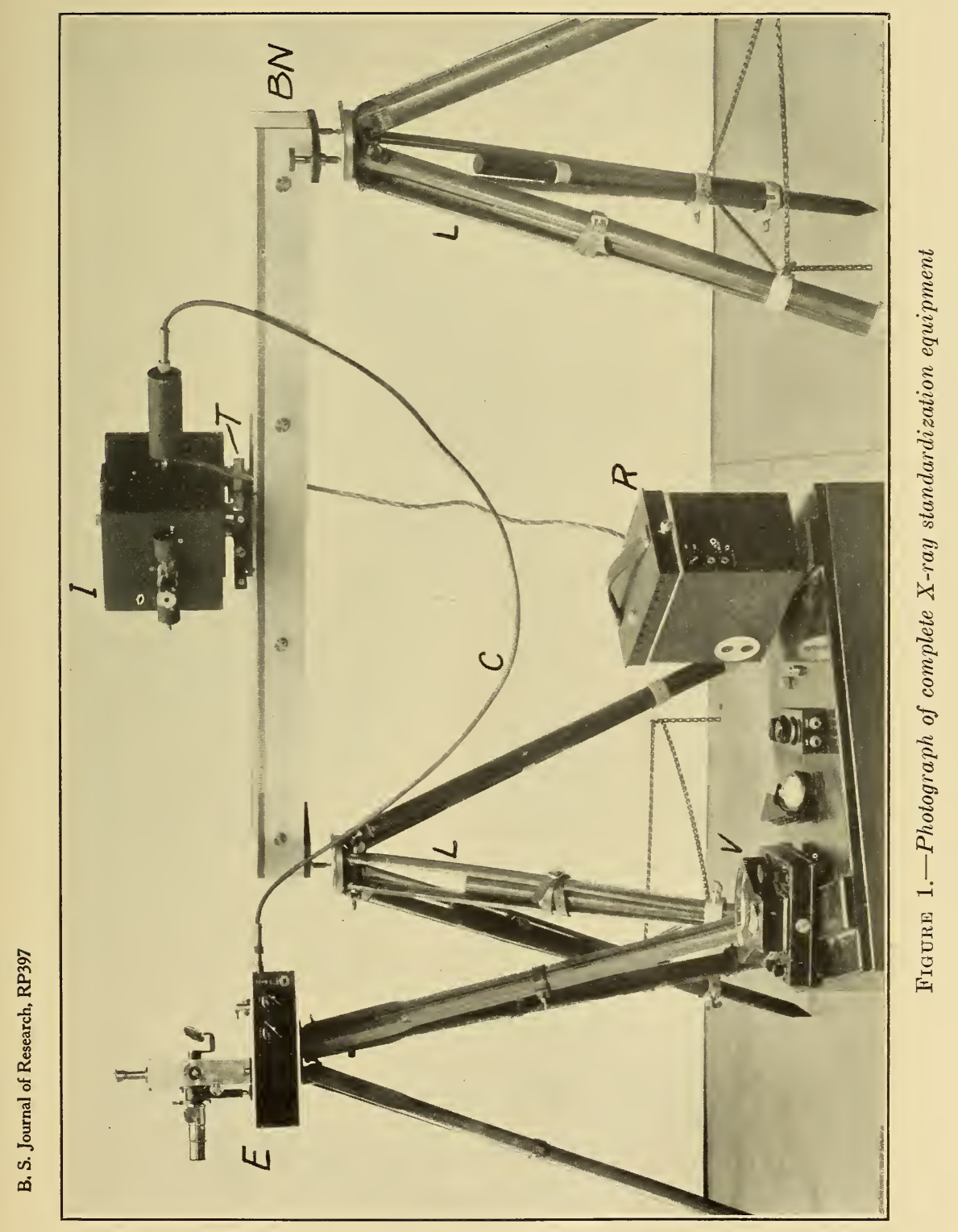




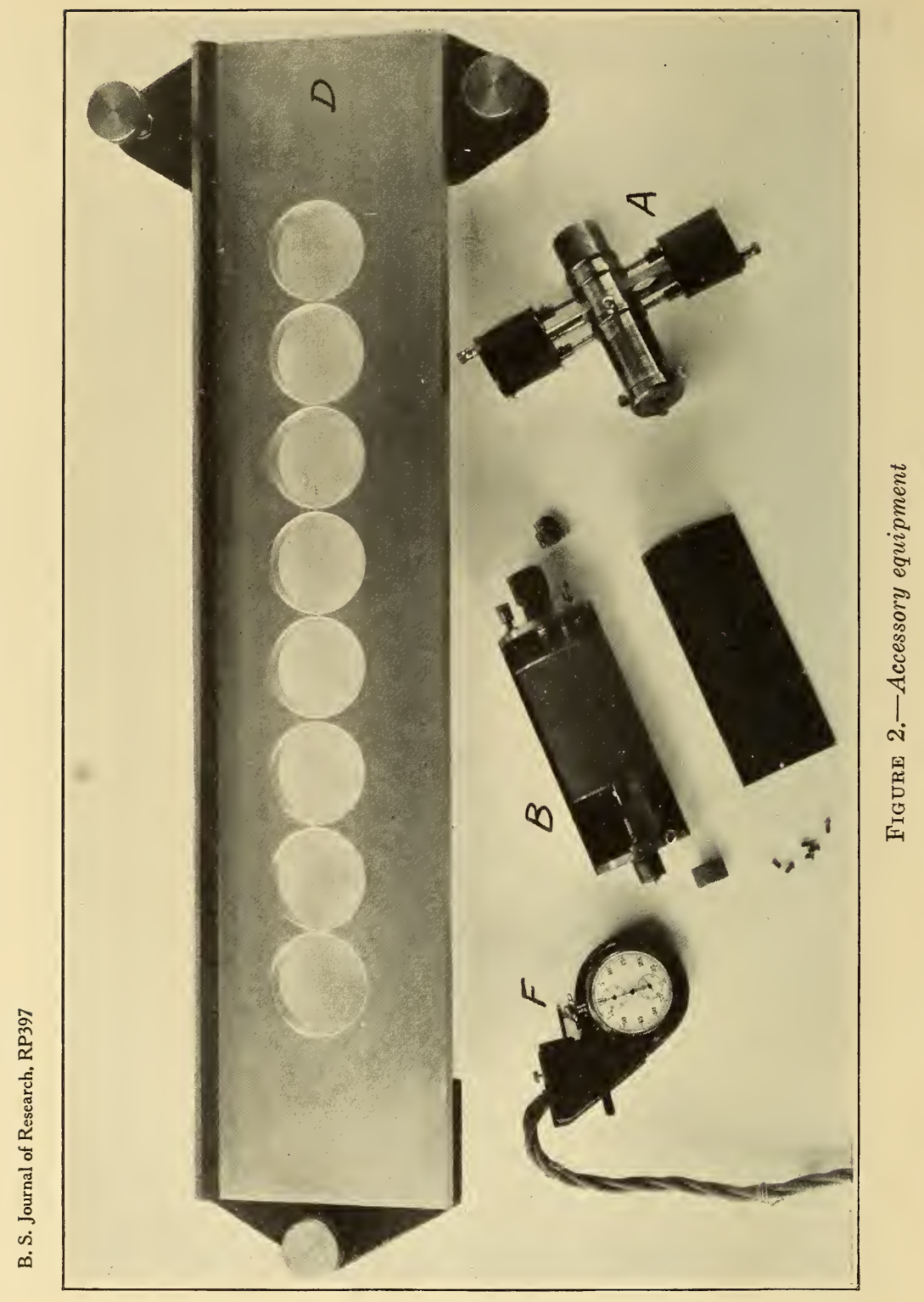


older potential dividing resistors of carbon were replaced by wirewound resistors.

The current-measuring system used ( $E$, fig. 1) has already been described. ${ }^{13} 14$ In this the electric charge furnished by the ionization chamber is entirely localized in a condenser having one plate connected to the ionization chamber collector electrode and the other to a source of continuously variable potential. The localization is is effected by maintaining the receiving line at a constant potential by properly changing the variable potential. This change in potential measures the accumulated charge. The null reading electrometer is connected to the ionization chamber, $I$, by a flexible rubber cable, $C$, surrounded by an earthed copper sheath. It may be noted that since, in the current measurements, the potential of the system is maintained at zero, cable leakage plays no part in the magnitude, but merely affects the sensitivity.

To derive the current, two different timing devices were used as circumstances demanded. The first was a magnetically operated lead shutter ( $A$, fig. 2$)$ to fix the exposure interval to the $\mathrm{X}$-ray beam entering the ionization chamber. The second was a magnetically operated switch, $B$, placed in the electrometer circuit to disconnect the measuring system from the ionization chamber. The second method is less desirable than the first because breaking the connection changes the capacity of the system; this requiring that the electric switch be operated only when the electrometer indicates zero potential, and that no adjustment of the compensator be made after opening the switch.

Both shutter and magnetic switch are operated and timed by means of a combined stop watch and 2-way switch. ( $F$, fig. 2.) The switch is adjusted to operate at the instant the stop watch is started and stopped, during which interval the operator balances the ionization current by changing the voltage, $V$, of the compensating condenser. The ratio of the compensating voltage, $V$, to the interval, $t$, is proportional to the ionization current.

Saturation voltage for the ionization chamber was supplied from a compact 2,000 -volt kenotron rectifier ( $R$, fig. 1$)$, having a filter capacity of $1 \mu \mathrm{f}$. The current drawn off by the potential divider for the guard wires, being only $4 \times 10^{-4}$ amperes, introduces no appreciable ripplage in the saturation voltage.

The ionization chamber was mounted on a swivel table and short cross slide, $T$, for adjustment in a direction at right angles to the beam in the horizontal plane; and the cross slide in turn mounted on an aluminum optical bench, $B N$, for adjustment along the beam. Two such benches were used-one 5 feet long, $B$, and the other about 20 inches $(D$, fig. 2). A pair of rugged adjustable tripods, $L$, were used for supporting the optical benches.

For transportation the entire equipment and a few spare parts were placed in the three cases. The two smaller ones containing the chamber, electrostatic compensator, $E$, and voltmeter, $V$, were carried by hand throughout the journey, while the large one, containing the accessories and 2,000-volt generator, was shipped.

13 L. S. Taylor, B. S. Jour. Research, vol. 6 (RP306), p. 807; 1931.

is L. S. Taylor, Radiology, vol. 17, p. 294; 1931. 


\section{ACCURACY OF CALIBRATION}

The accuracy of the compensator depends solely upon the fixed capacity in the compensator case. The calibration of this capacity was checked in each laboratory before using. The values of the calibration constant $k_{o}{ }^{15}$ as obtained at the various places, are given in Table 1. In addition, a complete calibration of the fixed capacity of the compensator was also carried out in Teddington, giving a value of $828.4 \mu \mu \mathrm{f}$ as compared with $828.2 \mu \mu \mathrm{f}$, obtained before leaving and after returning to Washington. In the final calibration, a variable capacity was used with its series of capacity differences accurate to within one-tenth per cent, and no deviation from the mean in any determination exceeded one-tenth per cent.

The voltmeter used for measuring the compensating potential was corrected to one-tenth per cent and a number of checks during the journey indicated that no changes occurred in transit.

TABLE 1.-Compensator calibration constants $\left(k_{\mathrm{o}}\right)$ obtained in different laboratories

\begin{tabular}{|c|c|}
\hline & $k_{0}$ \\
\hline $\begin{array}{l}\text { WashingtonI(Mays 1, 1931) } \\
\text { Teddington (N. P. L.) } \\
\text { Berlin (P. T. R.) } \\
\text { Paris (L'Hopital St. Antoine) } \\
\text { Washington (Sept. 4, 1931) }\end{array}$ & $\begin{array}{l}1.045_{2} \\
1.0457 \\
1.045_{4} \\
1.0462 \\
1.045_{0}\end{array}$ \\
\hline
\end{tabular}

Our earlier investigations led to a definite set of requirements, which were being adhered to as closely as possible in all comparisons. First, a replacement method of measuring the radiation was chosen, since it eliminates any uncertainty as to quality variations over the area of the beam. Then it was necessary to have the X-ray beam uniform over the area of the chamber diaphragm. Experience has shown that this must be tested for each set-up; visual alignment may lead to error.

Corrections for loss of radiation by absorption in the air between. the chamber diaphragm and collector electrode were also considered necessary, though with the guarded field chamber this correction has been reduced to a minimum which is negligible for the highly filtered radiations. With some of the larger air chambers, however, this can not be neglected anywhere within the practical range of wave lengths.

Data for the absorption of heterogeneous radiation in air are very incomplete; hence it was deemed necessary to interpolate between known coefficients for many radiation qualities encountered. ${ }^{1617}$ The values in this work so obtained are probably accurate to within about 15 per cent.

\section{COMPARISONS IN THIS COUNTRY}

Measurements have been previously described which show an average agreement between the large open-air ionization and the earlier guarded field (12-wire) chamber closer than 0.1 per cent. ${ }^{18}$

$15 k_{0}$ is the ratio of the potentials $V_{0} / v_{0}$ where $v_{0}$ is the potential induced on the insulated system by the application of $V_{0}$ to the compensator condenser, when all external capacities are removed from the compensator. A determination of $k_{\text {o }}$ serves as a check on the calibration of the capacity.

${ }_{16} \mathrm{M}$. Siegbahn, The Spectroscopy of X Rays, Appendix, Table 3, Oxford University Press; 1925.

17 L. S. Taylor and G. Singer, B. S. Jour. Research, vol. 6 (RP271), p. 219; 1931.

18 L. S. Taylor and G. Singer, B. S. Jour. Research, vol. 5 (RP211), p. 507; 1930. 
Comparisons between the earlier 12-wire chamber and the present 8-wire chamber showed agreement within 0.2 per cent.

In cooperation with Dr. G. Failla, a comparison of the bureau's current-measuring system with that of Memorial Hospital, of New York, ${ }^{19}$ was made, theirs being the only laboratory in this country using null compensation methods. This was primarily to be certain that our system would stand transportation. For comparison the B. S. compensator was simply connected directly to Failla's calibrated radium-ionization chamber. With a steady potential applied to the radium chamber, the resultant current was compensated for a convenient length of time. Measurements over a 20 -fold range of current are given in Table 2.

It will be noticed that the small differences are progressive- the radium-compensator readings becoming more negative with respect to bureau readings as smaller currents were used.

TABLE 2.-Comparison of compensators with Memorial Hospital

\begin{tabular}{|c|c|c|c|}
\hline Radium compensator & $\begin{array}{l}\text { Electro- } \\
\text { static } \\
\text { compen- } \\
\text { sator }\end{array}$ & $\begin{array}{c}\text { Per cent } \\
\text { difference }\end{array}$ & $\begin{array}{l}\text { A verage } \\
\text { deviation, } \\
\text { Bureau of } \\
\text { Standards }\end{array}$ \\
\hline $\begin{array}{c}\text { e.s. } u . \\
13.11 \text {. } \\
0.59787 \\
-\end{array}$ & \multirow[t]{2}{*}{$\begin{array}{l}\text { e. s. } u \text {. } \\
13.18 \\
1.242 \\
.593\end{array}$} & $\begin{array}{r}-0.53 \\
+.24 \\
+.66\end{array}$ & $\begin{array}{r}\text { Per cent } \\
\pm 0.9 \\
\pm .2 \\
\pm .2\end{array}$ \\
\hline A verage. & & +.12 & 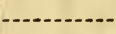 \\
\hline
\end{tabular}

\section{COMPARISON WITH NATIONAL PHYSICAL LABORA- TORY}

(With the cooperation of Dr. G. W. C. Kaye and W. Binks)

The new N. P. L. chamber is of the Duane type with a $10 \mathrm{~cm}$ plate spacing. A diagram of the set-up for making the comparison is shown in Figure 3. Their X-ray tube, of the Coolidge deep therapy type, was in a horizontal lead box with a limiting diaphragm, $A, 12$ $\mathrm{mm}$ in diameter at about $40 \mathrm{~cm}$ from the target. The ionizationchamber diaphragm, $B$, was $8 \mathrm{~mm}$ in diameter. The collector electrode, $C$, had a nominal effective length of $8 \mathrm{~cm}$ and its center was approximately $35 \mathrm{~cm}$ from the diaphragm. They used a null electrostatic compensator to measure the ionization current. Both ionization chambers were mounted on a short cross slide, which was in turn mounted on a heavy optical bench. (It happened that the bureau chamber fitted exactly on the N. P. L. track.) The replacement method of observation was used, the two chambers being shifted alternately into position for observation. This distance was so fixed that the front face of the chamber diaphragm was in both cases at the same distance from the target-about $100 \mathrm{~cm}$.

Curve I (fig. 4) shows in arbitrary units the distribution of intensity across the $\mathrm{X}$-ray beam as obtained by moving the chamber across it. It should be pointed out that the relative narrowness of such a peak is largely due to the effective slit width of the chamber diaphragm used to "explore" the beam. Some measurements made with a 
smaller diaphragm indicated a more nearly uniform distribution. In any case both chambers were very sensitive to alignment. The operating position of the chambers in the beam is indicated by the arrow.

The two compensating systems were separately compared by using them alternately to measure the ionization in the N.P. L. chamber while the X-ray output was maintained constant according to meter readings. In this comparison the $\mathrm{B}$. $\mathrm{S}$. instrument read 1.47 per cent higher than that of the N. P. L.

During the comparison of chambers it was found that the chamber diaphragms of the two equipments had different effective areas not accounted for by the difference in their diameter. The N. P. L.

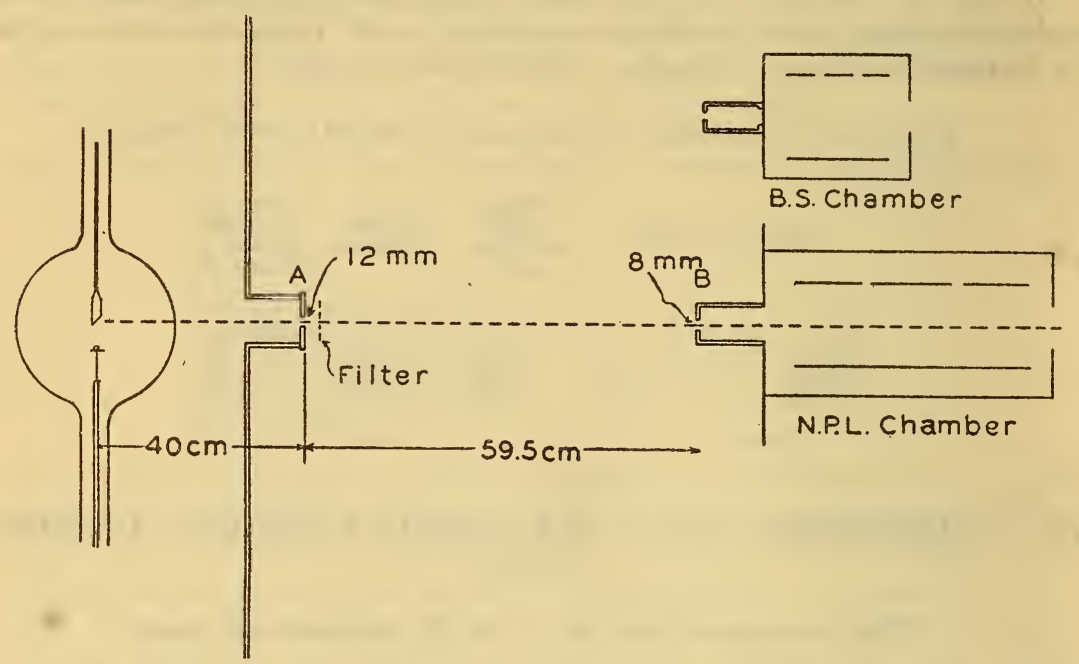

Figure 3.-Diagram of X-ray system in Teddington

diaphragm was about $9 \mathrm{~mm}$ thick and the hole was cylindrical as indicated in Figure 5, $A$. The B. S. diaphragm ( $B$, fig. 5$)$ had a taper of $0.02 \mathrm{~mm}$ per millimeter length and was only about $4 \mathrm{~mm}$ thick along the face of the hole. Depending upon such factors as the focal spot diameter and the distance from target to diaphragm, the two types of diaphragms were found to yield different results. Some measurements made at the same time by the laboratory in Washington, and described below, illustrate this variation.

* As dictated by the type of construction, the difference in the distance between the diaphragm and center of the collector for the two chambers amounts to about $15 \mathrm{~cm}$, hence the comparatively soft radiation used necessitated corrections for air absorption. These were obtained by interpolation from previous data. ${ }^{20}$ 


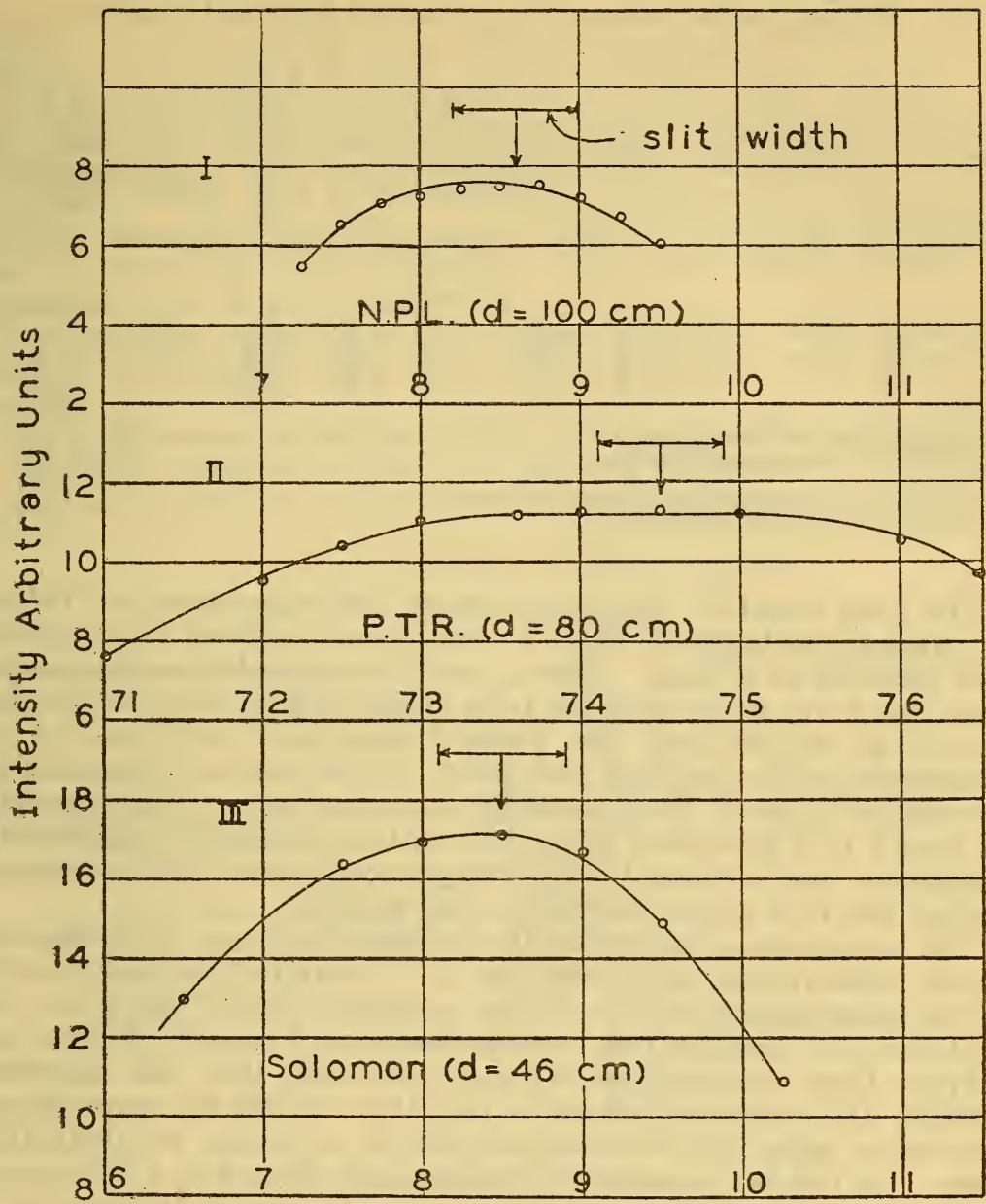

Cross scale $(\mathrm{cm})$

FIGURE 4. $-X$-ray intensity distribution across $X$-ray beams
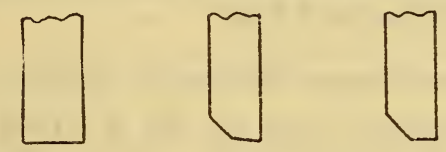

$\square$
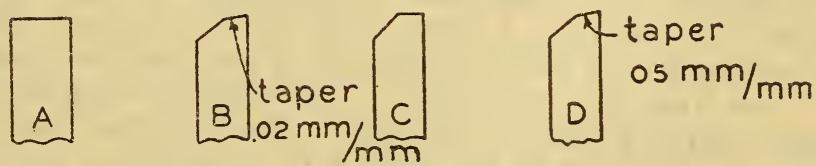

Straight drilled Beveled Backs

tapered straight tapered

FIGURE 5.-Types of diaphragms used 
TABLE 3.-Comparisons with the National Physical Laboratory

\begin{tabular}{|c|c|c|c|c|c|c|c|c|c|c|c|}
\hline Run & $\mathrm{Kv}$ & $\begin{array}{l}\text { Filter } \\
\text { Cu. }\end{array}$ & $\begin{array}{l}\text { H. V. L. } \\
\text { (copper) }\end{array}$ & $\begin{array}{l}\text { Ob- } \\
\text { served } \\
\text { r/min } \\
\text { B.S. }\end{array}$ & $\begin{array}{c}\text { Ob- } \\
\text { served } \\
\text { r/min } \\
\text { N.P.L. }\end{array}$ & $\begin{array}{c}\text { Air } \\
\text { absorp- } \\
\text { tion } \\
\text { cor- } \\
\text { rection }\end{array}$ & $\begin{array}{l}\text { Cor- } \\
\text { rected } \\
\text { for air } \\
\text { absorp- } \\
\text { tion }\end{array}$ & $\begin{array}{l}\text { B.S.l } \\
\text { N.P. L. } \\
\text { per cent } \\
\text { differ- } \\
\text { ence after } \\
\text { correc- } \\
\text { tion }\end{array}$ & $\begin{array}{c}\text { Cor- } \\
\text { rected } \\
\text { for } \\
\text { dia- } \\
\text { phragms }\end{array}$ & $\begin{array}{l}\text { B. S./ } \\
\text { N. P.L. } \\
\text { per cent } \\
\text { differ- } \\
\text { ence after } \\
\text { correc- } \\
\text { tion }\end{array}$ & $\begin{array}{l}\text { B.S. } \\
\text { pre- } \\
\text { cision }\end{array}$ \\
\hline$\therefore$ & $\begin{array}{l}110 \\
110 \\
143 \\
110 \\
110\end{array}$ & $\begin{array}{l}0 \\
0 \\
0.14 \\
0\end{array}$ & $\begin{array}{l}0.11 \\
.11 \\
.5 \\
.11 \\
.11\end{array}$ & $\begin{array}{l}\text { 4. } 30 \\
\text { 4. } 51 \\
\text { 1. } 295 \\
\text { 4. } 32 \\
4.24\end{array}$ & $\begin{array}{l}\text { 3. } 98 \\
4.13 \\
1.205 \\
4.14 \\
4.08\end{array}$ & $\begin{array}{r}\text { Per cent } \\
1.5 \\
1.5 \\
.6 \\
1.5 \\
1.5\end{array}$ & $\begin{array}{l}4.04 \\
4.19 \\
1.21 \\
4.20 \\
4.14\end{array}$ & $\begin{array}{l}-6.2 \\
-7.4 \\
-6.4 \\
-2.82 \\
-2.39\end{array}$ & $\begin{array}{l}4.26 \\
4.33 \\
1.28\end{array}$ & $\begin{array}{l}-0.93 \\
-1.9 \\
-1.32 \\
-2.82 \\
-2.39\end{array}$ & $\begin{array}{c}\text { Per } \\
\text { cent } \\
\pm 1.2 \\
\pm .7 \\
\pm .9 \\
\pm 1.1 \\
\pm .8\end{array}$ \\
\hline \multicolumn{10}{|c|}{$\begin{array}{l}\text { A verage difference of intact systems } \\
\text { Corrected for compensator differences. }\end{array}$} & $\begin{array}{r}-1.38 \\
+.09\end{array}$ & \\
\hline \multicolumn{10}{|c|}{$\begin{array}{l}\text { A verage difference when using the same diaphragms } \\
\text { Corrected for compensator differences. }\end{array}$} & $\begin{array}{l}-2.61 \\
-1.14\end{array}$ & \\
\hline
\end{tabular}

The final results of the comparisons are summarized in Table 3. In giving percentages the N.P. L. readings are referred to the guarded field chamber as a basis. Runs 1 and 2 are straightforward comparisons; run 3 was made with the tube diaphragm increased in diameter from 12 to $30 \mathrm{~mm}$; and runs 4 and 5 were made with the B. S. diaphragms on both chambers, and, hence, in this case no diaphragm area corrections of the N. P. L. readings were necessary. This correction for runs 1 to 3 amounted to 5.4 per cent as obtained experimentally. Because of the fact that the diaphragm corrections were unnecessary the last two runs are probably the most reliable.

The last column, indicating the average deviation from the mean for the observations made with the B. S. chamber, reveals the effect of the unsteadiness of the X-ray generator, since under the best conditions of operation this average deviation is about \pm 0.2 per cent.

From these comparisons we may conclude that the agreement between the chambers alone is probably within the experimental error when using the same diaphragms or correcting for their differences. As the two chambers initially stood there was a difference of some 9 per cent which was reduced only by the corrections for air absorption, diaphragms, and compensator differences.

\section{COMPARISON WITH THE PHYSIKALISCH-TECHNISCHE REICHSANSTALT}

(With the cooperation of Doctors Behnken and Jaeger)

The standard ionization chamber used by the P. T. R. is of the large cylindrical type described by Behnken..1 Their X-ray tube is supported vertically in a large lead box. (Fig. 6.) The limiting tube diaphragm is a $3 \mathrm{~cm}$ opening in a lead rubber cylinder placed about $5 \mathrm{~cm}$ from the tube walls. The chamber diaphragm is of the cylindrical type, $7 \mathrm{~mm}$ in diameter. The collector electrode of the ionization chamber is $30 \mathrm{~cm}$ long with its center approximately 40 $\mathrm{cm}$ from the chamber diaphragm. An uranium oxide compensator with a null electrometer indicator is used to balance the ionization 
current. ${ }^{22}$ Their chamber was mounted on a table movable on a track on the floor in a direction parallel to the beam.

The B. S. chamber was mounted on the long optical bench, supported on two tripods, placed at right angles to the beam and at such a height that the $P$. T. R. chamber in taking its forward position could pass above it. In the operating position the distance from target to chamber diaphragm and the section of the beam intercepted was the same for both chambers. The replacement method of observation was also used here.

To check the constancy of the output of the X-ray tube, a thimble chamber was maintained in the beam just off the axis as shown in Figure 6.

The distribution of intensity across the X-ray beam as obtained by the B. S. chamber is shown in Curve II of Figure 4 . The beam is seen to be uniform within experimental limits over a wide area,

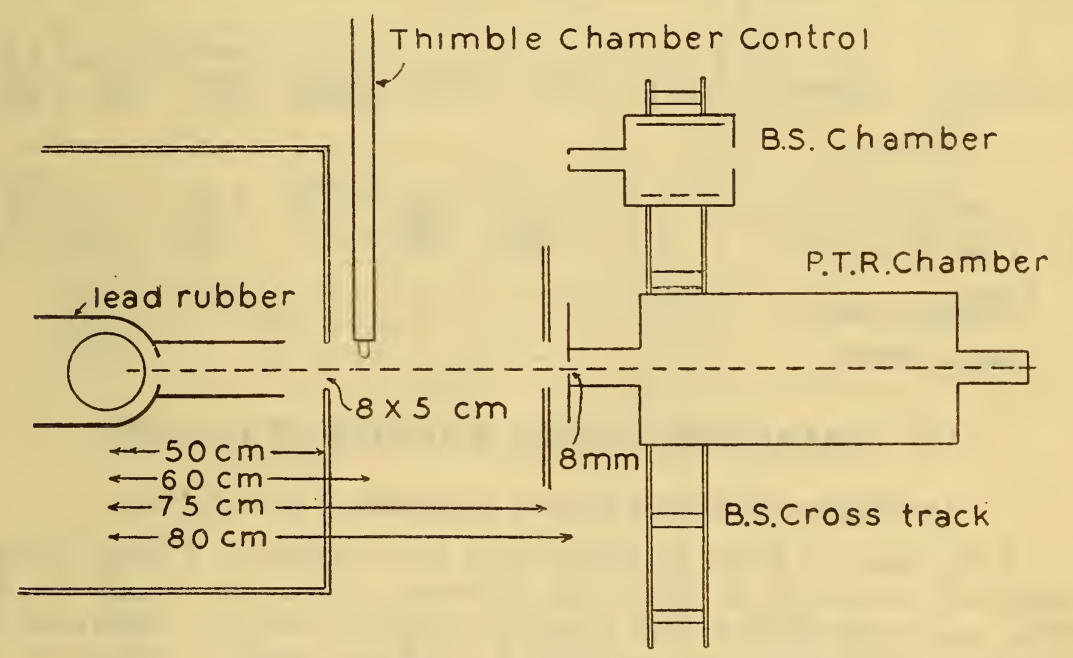

FIGURE 6.-Diagram of X-ray system in Berlin

so that a critical alignment of the chambers was not necessary. The working position of both chambers is indicated by the arrows.

The diaphragms of the two chambers had the same thickness, so a negligible difference arising therefrom is to be expected. This proved to be the case as indicated by some subsequent measurements.

The difference in the distances between chamber diaphragm and center of collector for the two chambers was $20 \mathrm{~cm}$. Comparatively hard radiations, entailing small air absorption corrections, were used in most of the measurements.

The electrostatic and uranium oxide compensators were compared directly in the same manner as with Failla. The results are given in Table 4, referred to the B. S. compensator as a basis.

The P. T. R. compensator registers a somewhat smaller magnitude than the B.S. compensator. It will also be noted that the variations are progressive, but in the opposite direction from Failla's. The range of currents in this case is about one-tenth that used in Failla's laboratory. 
TABLE 4.-Comparison of compensators at the Physikalisch-Technische Reichsanstalt

\begin{tabular}{|c|c|c|c|}
\hline $\begin{array}{l}\text { Uranium oxide current } \\
\text { amp } \times 10^{-12}\end{array}$ & $\begin{array}{c}\text { Electro- } \\
\text { static com- } \\
\text { pensator } \\
\text { amp } \times 10^{-12}\end{array}$ & Difference & $\begin{array}{c}\text { Average } \\
\text { deviation } \\
\text { from mean }\end{array}$ \\
\hline $\begin{array}{l}133- \\
206 \\
280\end{array}$ & $\begin{array}{l}134.0 \\
207.1 \\
281.2\end{array}$ & $\begin{array}{r}\text { Per cent } \\
+0.75 \\
+.53 \\
+.43\end{array}$ & $\begin{array}{r}\text { Per cent } \\
\pm 0.31 \\
\pm .60 \\
\pm .57\end{array}$ \\
\hline A verage_. & .......... & +.58 & \\
\hline
\end{tabular}

The comparison as a whole is given in Table 5. The only corrections made were for air absorption in the P. T. R. chamber.

TABLE 5.-Comparison with the Physikalische-Technischen Reichsanstalt

\begin{tabular}{|c|c|c|c|c|c|c|c|c|c|}
\hline Run & $\mathrm{KV}$ & Filter & $\begin{array}{l}\text { H. V. L. } \\
\mathrm{mm} \text { Cu }\end{array}$ & $\begin{array}{l}r / \min \\
\text { B.S. }\end{array}$ & $\begin{array}{l}r / \min \\
\text { P.T.R. }\end{array}$ & $\begin{array}{c}\text { Air ab- } \\
\text { sorption } \\
\text { correction }\end{array}$ & $\begin{array}{l}\text { Corrected } \\
\text { for air } \\
\text { absorp- } \\
\text { tion }\end{array}$ & $\begin{array}{l}\text { Per cent } \\
\text { differ- } \\
\text { ence }\end{array}$ & $\begin{array}{l}\text { B. S. } \\
\text { preci- } \\
\text { sion }\end{array}$ \\
\hline 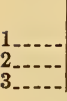 & $\begin{array}{l}100 \\
150 \\
180\end{array}$ & $\begin{array}{l}2.0 \mathrm{Al} \\
0.5 \mathrm{Cu}+1.0 \mathrm{Al} \\
0.7 \mathrm{Cu}+1.0 \mathrm{Al}\end{array}$ & $\begin{array}{l}0.16 \\
.75 \\
1.1\end{array}$ & $\begin{array}{r}0.0515 \\
.0457 \\
.0176\end{array}$ & $\begin{array}{r}0.0503 \\
.0460 \\
.0471\end{array}$ & $\begin{array}{r}\text { Per cent } \\
1.2 \\
.6 \\
.4\end{array}$ & $\begin{array}{r}0.0509 \\
.0463 \\
.0473\end{array}$ & $\begin{array}{r}-1.17 \\
+1.11 \\
-.68\end{array}$ & $\begin{array}{c}\text { Per cent } \\
\pm 0.38 \\
\pm .5 \\
\pm .25\end{array}$ \\
\hline \multicolumn{9}{|c|}{$\begin{array}{l}\text { A verage- } \\
\text { Compensator correction }\end{array}$} & \\
\hline & & fierence & & & & & & +.35 & \\
\hline
\end{tabular}

\section{COMPARISON WITH FRENCH STANDARD}

(At l'Hôpital St. Antoine with the cooperation of Dr. I. Solomon)

At the time of these measurements the recognized French X-ray standard measured in terms of Solomon's unit, known as the $R$. This was accomplished with a specific thimble chamber calibrated in terms of the ionization produced by radium under a given set of conditions. ${ }^{23}$

Differences in the apparatus, and the general experimental conditions, necessitated a comparison procedure different from that followed with N. P. L. and P. T. R. A fairly broad X-ray beam was used as a source, and measurements made with the two chambers simultaneously in two different parts of the beam. This necessitated placing the Solomon chamber in the beam sufficiently far off the axis so that it did not affect in any way the radiation entering the $B$. S. chamber. This position was such that it was impossible to see the thimble chamber when sighting back through the B. S. diaphragms.

The X-ray tube was placed in a horizontal oil-filled tank so that the radiation passed through a constant filter of $20 \mathrm{~mm}$ of oil $+1.0 \mathrm{~mm}$ of aluminum. The tube tank was not sufficiently adjustable to provide a horizontal X-ray beam; and, since the B. S. equipment could not well be used vertically, the beam was brought out at an angle of about $30^{\circ}$ with the horizontal. The short optical bench supported by tripods of different heights was inclined at this angle, as sketched in Figure 7. The limiting diaphragm, was about $3 \mathrm{~cm}$ in diameter.

${ }^{23}$ I. Solomon, J. de Rad. et d'Elec., vol. 8, p. 851; 1924; vol. 10, p. 155; 1926; vol. 11, p. 286; 1927. 
The thimble chamber had an effective length of about $3 \mathrm{~cm}$ and was placed $44.5 \mathrm{~cm}$ from the X-ray tube target and just off the center of the beam entering the B.S. chamber. The front diaphragm of the B. S. chamber was $58.2 \mathrm{~cm}$ from the X-ray tube target. As checked later, radiation scattered from the $\mathrm{B}$. S. chamber did not produce a detectable effect on the thimble chamber readings.

Curve III in Figure 4 shows the distribution of intensity across the $\mathrm{X}$-ray beam as obtained by the B. S. chamber. The working positions of both chambers are indicated by the arrows.

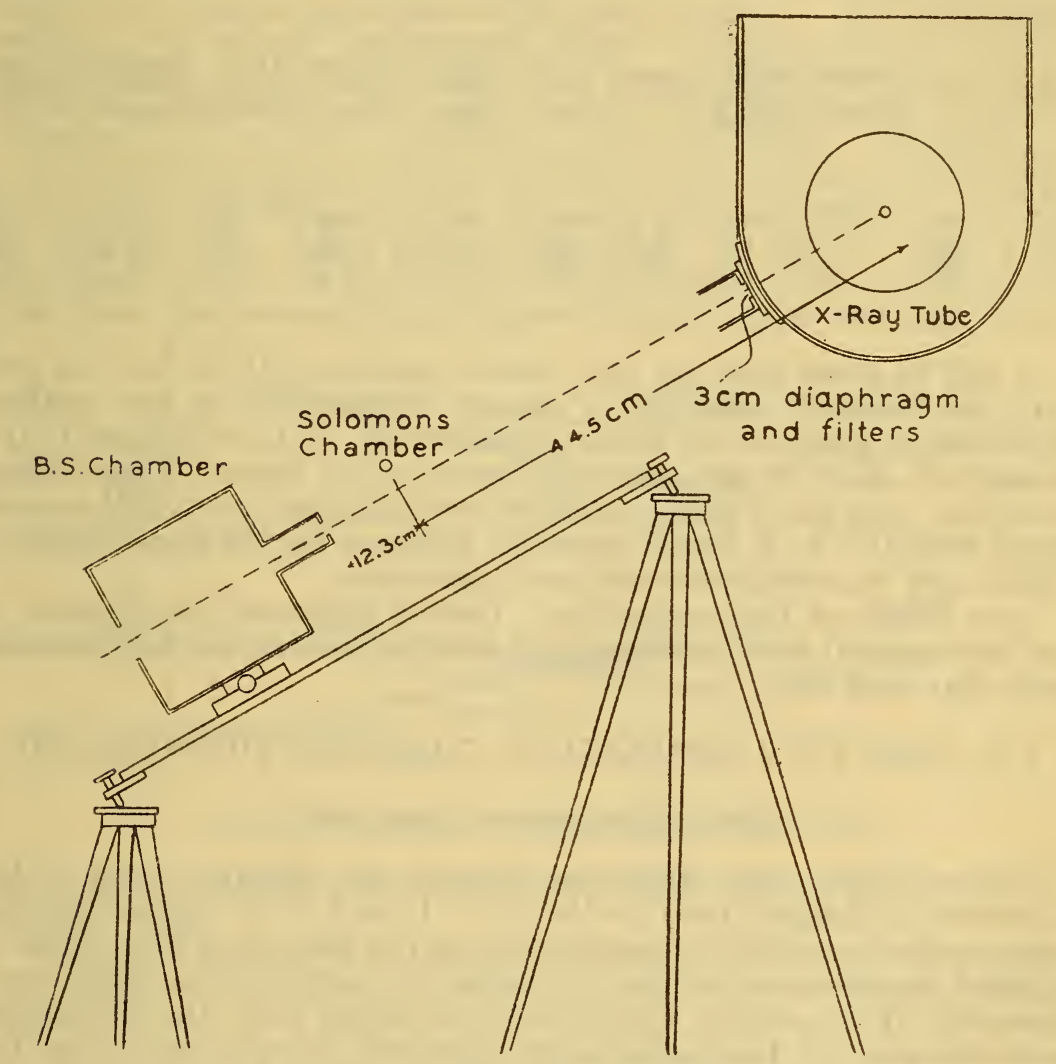

Figure 7.-Diagram of $X$-ray system in Paris

Corrections are necessary in this case for the inverse square law and air absorption. The former was applied for the difference in distance of the thimble chamber axis and the front of the B. S. chamber diaphragm from the target. This required that the readings of the thimble chamber be multiplied by a factor of 0.585 . The latter was applied for the distance between thimble chamber and the B. S. collector electrode - a distance of approximately $26 \mathrm{~cm}$. Absorption coefficients were taken from available data. However, as a rough check on these corrections they were also obtained experimentally by moving the thimble chamber in a direction along the beam axis. This could not be done with very great accuracy, but the results indicated the corrections used to be valid within the experimental limits. 
A further correction for temperature and pressure is necessary in this case because the Solomon unit is defined for room temperature. Since the measurements were made at $19^{\circ} \mathrm{C}$. and $762 \mathrm{~mm}$ mercury, a factor of 6.97 per cent was applied to the B. S. chamber readings. The average deviation from the mean for all the observations was about \pm 0.4 per cent.

Table 6 gives the results.

TABLE 6.-Comparison with Dr. I. Solomon at L'Hopital St. Antoine

\begin{tabular}{|c|c|c|c|c|c|c|c|c|c|c|}
\hline Run & $\mathrm{K} \nabla$ & $\begin{array}{c}\text { Filter (mm) } \\
\text { ( }+1.0 \mathrm{Al}+ \\
20 \mathrm{~mm} \text { oil })\end{array}$ & $\begin{array}{l}\text { Half- } \\
\text { value } \\
\text { layer in } \\
\text { copper }\end{array}$ & $\begin{array}{l}\mathrm{r} / \mathrm{min} \\
\mathrm{B} . \mathrm{S} .\end{array}$ & $\begin{array}{l}R / \mathrm{min} \\
\text { Solo- } \\
\text { mon }\end{array}$ & $\begin{array}{l}\text { Corrected } \\
\text { for in- } \\
\text { verse } \\
\text { square } \\
\text { law }\end{array}$ & $\begin{array}{c}\text { Corrected } \\
\text { for } \\
\text { leakage }\end{array}$ & $\begin{array}{l}\text { Air ab- } \\
\text { sorption } \\
\text { correction }\end{array}$ & $\begin{array}{l}\text { Corrected } \\
\text { for air ab- } \\
\text { sorption }\end{array}$ & $\begin{array}{l}\text { B. S. unit } \\
\text { ratio } \\
\text { Sol. unit }\end{array}$ \\
\hline . & $\begin{array}{l}110 \\
150 \\
190 \\
190\end{array}$ & $\begin{aligned} & C u . \\
& .4 \\
& .5 \\
& 1.0\end{aligned}$ & $\begin{array}{l}0.25 \\
.75 \\
1.0 \\
1.5\end{array}$ & $\begin{array}{l}5.81 \\
3.47 \\
5.95 \\
3.85\end{array}$ & $\begin{array}{l}22.5 \\
14.5 \\
24.8 \\
16.0\end{array}$ & $\begin{array}{r}13.15 \\
8.48 \\
14.50 \\
9.37\end{array}$ & $\begin{array}{r}12.49 \\
8.06 \\
13.77 \\
8.90\end{array}$ & $\begin{array}{r}\text { Per cent } \\
0.5 \\
1.0 \\
1.5 \\
2.5\end{array}$ & $\begin{array}{r}12.18 \\
7.94 \\
13.63 \\
8.85\end{array}$ & $\begin{array}{l}2.10 \\
2.28 \\
2.29 \\
2.30\end{array}$ \\
\hline
\end{tabular}

It will be noted that for the harder radiation $(H$. V. L. $=1.0 \mathrm{~mm}$ $\mathrm{Cu}$ ) the Solomon chamber is almost independent of the quality. However, in going to the softer radiation $(\mathrm{H} . \mathrm{V} . \mathrm{L} .=0.25 \mathrm{~mm} \mathrm{Cu}$ ) a change of about 9 per cent apparently takes place. Considering, therefore, only the harder radiation, we find that $1 r=2.29 R$ as compared with $1 r=2.2 R$, found earlier by Solomon for the same chamber, which may be considered very good agreement.

As a result of this comparison, Doctor Solomon has adopted as his fundamental standard a guarded field ionization chamber identical with that used here.

\section{STUDY OF IONIZATION CHAMBER DIAPHRAGMS}

(By G. Singer, Bureau of Standards) ${ }^{24}$

The relatively large difference between the effective areas of the chamber diaphragms used by the N. P. L. and B. S. was unexpected, since earlier ionization measurements at the Bureau of Standards on tapered diaphragms had not indicated any appreciable difference..$^{25}$ However, if the source of radiation be larger than the diaphragm aperture some of the radiation incident on the opening strikes the cylindrical wall of the hole in the diaphragm and is effectively cut off as illustrated in Figure 8, $a$. This shifts the effective target-diaphragm position from the outer face toward the inner face of the diaphragm, as well as causing an effective shrinking of the diaphragm opening.

The taper diaphragm (fig. $8, b$ ) does not present this difficulty if used far enough from the target to prevent radiation hitting the wall of the aperture. It has the disadvantage, however, of introducing arbitrary factors in the diaphragming system. Furthermore, with steep tapers the front edge of the diaphragm may actually transmit some radiation.

24 Washington, June 28, 1931.

${ }_{26}$ L. S. Taylor and G. Singer, B. S. Jour. Research, vol. 4 (RP169), p. $\$ 631 ; 1930$. "In reviewing this work it was found that the experimental conditions were not sufficiently like those described above to warrant comparison. 
As a result of the discrepancy between the N. P. L. and B. S. measurements, three carefully constructed diaphragms of the types shown in Figure $5 A, C$, and $D$, were compared at the Bureau of Standards. These were used successively on the ionization chamber at a distance of $100 \mathrm{~cm}$ from the target and ionization measurements made for the same X-ray output.

The actual measurements of the diaphragms are given in Table 7. Diaphragms $A$ and $C$ were both drilled and reamed without taper in lead-bismuth plates $10 \mathrm{~mm}$ thick, $C$ then being beveled off at the back so as to give a resultant thickness of $4 \mathrm{~mm} .{ }^{26}$ From the explanation given above they should differ in transmission by roughly 1.2 per cent. The diaphragm $B$ was the same as those used on the B. S. chamber in Europe, having a taper of $0.02 \mathrm{~mm}$ per millimeter on the radius and a thickness of $4 \mathrm{~mm}$ up to the bevel. Diaphragm $B$ at a distance of $100 \mathrm{~cm}$ from the target should transmit all the radiation incident on the front of the aperture; and neglecting transmission through its edges should pass approximately 0.4 per cent more radiation than the thin straight-walled diaphragm $C$. The diaphragm $D$ had about two and one-half times the taper of $B$, and was used in

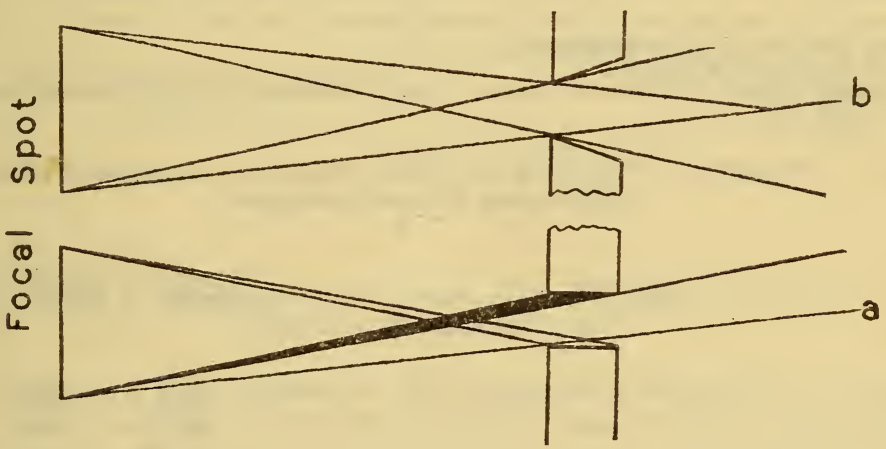

FIGURE 8.-Effect of thick and tapered diaphragms

these measurements solely to bring out more clearly the effect of the tapered walls.

To compare the effective areas or transmissions of these diaphragms the volume of air ionized within the chamber is calculated from the measurements of the diaphragm diameter, and from which in turn is determined the ionization per cubic centimeter $\left(I_{c c}\right)$ of air. ${ }^{27} I_{c c}$ is, of course, directly proportional to the effective diaphragm opening. The results are given in Table 8.

The diaphragm $C$ (thin, straight walls) is used as a base in the experimental and calculated values of $I_{c c}$ both being taken as 100 . The agreement between the two sets of values is as close as may be expected. It is seen, however, that the difference between $A$ and $B$ is only 1.7 per cent, whereas, at the N. P. L. the experimentally determined difference between essentially similar diaphragms was apparently 5.4 per cent. A possible cause of this discrepancy may lie in errors in the measurements of the diaphragms as shown below.

The accurate measurement of the diameters of the apertures presented some unexpected difficulties. The B. S. tapered dia-

${ }^{26}$ This type of diaphragm has always been used in previous experiments at the Bureau of Standards.

27 L. S. Taylor, B. S. Jour. Research, vol. 3 (RP119), p. 807; 1929. 
phragms were measured by a method described by Failla ${ }^{28}$ wherein an accurately known tapered mandrel was forced into the leadbismuth diaphragm a given distance. Binks measured two of our diaphragms while at Teddington, with a micrometer microscope, and found diameters of 8.005 and $8.035 \mathrm{~mm}$, respectively, whereas, they were both supposed, from mandrel measurements, to be $8.000 \mathrm{~mm}$.

TABLE 7.-Diameter measurements of lead-bismuth alloy diaphragms made by Bureau of Standards gage section

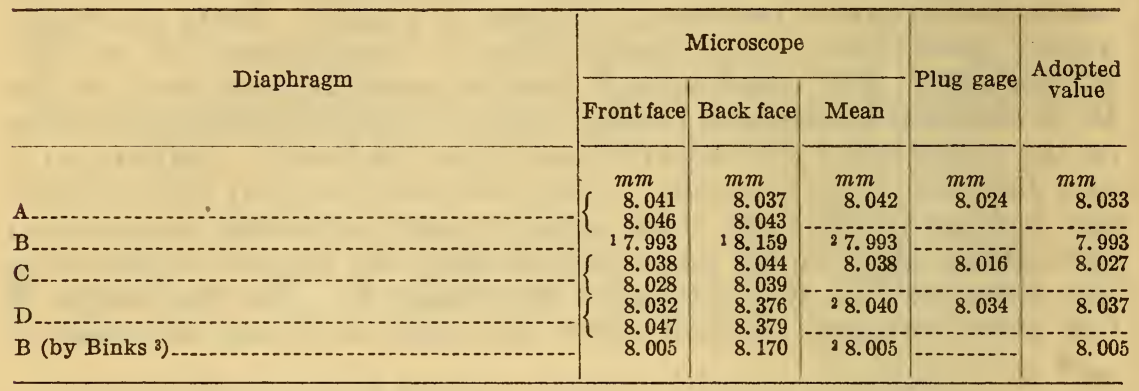

1 Average of readings taken for 6 diameters.

2 A verage for diameter of front face.

3easurements made by Binks in Teddington. It will be noted that they differ from our measurements by only 0.15 per cent.

TABLE 8.-Comparative ionizations per cubic centimeter of air obtained with different diaphragms $100 \mathrm{~cm}$ from target

\begin{tabular}{|c|c|c|c|}
\hline Diaphragm & $\begin{array}{c}\text { I/cc (experi- } \\
\text { mental) }\end{array}$ & $\begin{array}{l}I / c c \text { (calcu- } \\
\text { lated) }\end{array}$ & $\begin{array}{l}\text { Observa- } \\
\text { tional error }\end{array}$ \\
\hline B & $\begin{array}{l}98.6 \\
100.31 \\
100.0 \\
100.79\end{array}$ & $\begin{array}{r}98.8 \\
100.4 \\
100.0 \\
-\end{array}$ & $\begin{array}{l}\text { Per cent } \\
\quad \pm 0.17 \\
\pm .20 \\
\pm .17 \\
\pm .17\end{array}$ \\
\hline
\end{tabular}

To check the reliability of the microscope or other methods the diaphragms $A, B, C, D$, in Figure 5 were measured by the gage section of the Bureau of Standards ${ }^{29}$ using both the micrometer-microscope and plug-gage methods. Diaphragm $B$ is the same one measured by Binks. The results given in Table 7 , show that the micrometer microscope measurements are consistently larger than the plug-gage measurements. An explanation for this discrepancy is at once obvious from an exaggerated cross section of a diaphragm in Figure 9. The microscope method measures only the face diameter of the hole which is likely to be somewhat beveled or worn in the process of making. The plug gage, on the other hand, measures the diametral separation between the highest projecting ridges within the bore. The diameters used in the present study were the average from the two sets of measurements and are estimated by the gage section not to be in error by more than one-tenth per cent.

It should be mentioned that even when using hard lead it was found impossible to make circular holes. Warping tended invariably to

28 G. Failla, Am. J. Roent. and Ra. Ther., vol. 21, p. 47; 1929.

20 We are indebted to Drs. L. V. Judson and D. R. Miller, of the Bureau of Standards gage section, for their willing cooperation in this work. 
make elliptically shaped openings. As a consequence the bureau is discontinuing the use of lead diaphragms and will in the future use a hard gold or lead-calcium alloy wherein the surface can be accurately lapped and be relied upon to hold its dimensions.

VIII. CONCLUSION-JOINT RECOMMENDATIONS OF THE BUREAU OF STANDARDS, NATIONAL PHYSICAL LABORATORY, PHYSIKALISCH-TECHNISCHE REICHSANSTALT, AND LE SERVICE D'ETALONNAGE DE L'HOPITAL ST. ANTOINE

Table 9 is given to summarize the results of all of the comparisons. The size of roentgen as measured by each laboratory is referred to that measured by the B. S. chamber as a base.

Thus the agreement between the National Laboratories is as close as may be reasonably expected and much better than necessary to-day for practical calibration purposes.

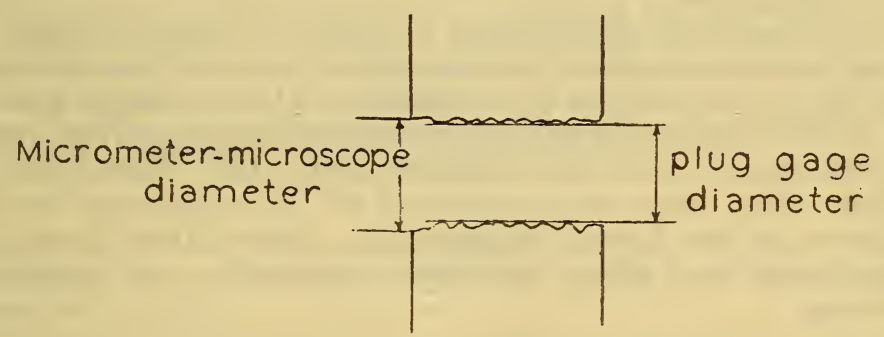

FIGURE 9.-Magnified cross section of diaphragm showing where diameter measurements apply

The National Laboratories feel justified, therefore, in making certain recommendations which should be met by all open-air ionization chambers in order to avoid gross errors. It is believed that these are neither restrictive nor unduly arbitrary. These are:

1. The use of an X-ray tube having a focal spot as small as possible (up to $8 \mathrm{~mm}$ diameter).

2. The use of a diaphragm placed as close to the tube as possible and having an aperture of such size as to shield from the ionization chamber all radiation except that from the face of the target.

TABLE 9.-Summary of comparisons made between the Bureau of Standards and foreign laboratories

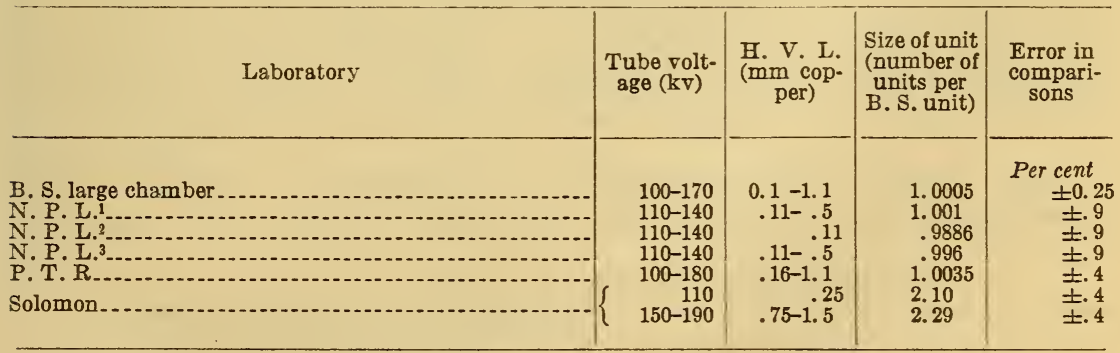

\footnotetext{
1 Corrections made for diaphragm differences.

2 Same diaphragm used on both chambers.

3 Averaging all resdings taken.
} 
3. The use of a standard chamber diaphragm having a minimum thickness, but such that not more than one-tenth of the radiation measured passes through the material of the diaphragm.

4. The use of a standard ionization chamber aperture of about the same diameter as the focal spot; however, not to be much smaller.

5. The utilization of only that portion of the X-ray beam in which the intensity within the experimental limits is uniform.

6 . The use of the shortest distance between chamber diaphragm and collector electrode.

7. The use of a current-measuring method wherein the potential difference between the guards and collector plate is negligible; preferably a null method.

Doctor Solomon has announced ${ }^{30}$ his acceptance of the open-air ionization chamber as his fundamental standard while at the same time recognizing the secondary calibration with radium as heretofore used by him. For this purpose he will employ an exact duplicate of the Bureau of Standards guarded field ionization chamber as used in this investigation.

In conclusion the author wishes to express his appreciation to the following persons whose wholehearted efforts and assistance have rendered this work possible in its entirety: Messrs. Singer and Stoneburner, of the bureau's X-ray laboratory for having carried out most of the preliminary tests and measurements; Mr. Rhinebold, of our instrument shop, who constructed all of the apparatus; and those investigators in the foreign laboratories whose names have already been mentioned and whose complete cooperation was essential and forthcoming.

Washington, October 1, 1931.

so Proceedings of Committee on X-Ray Units of Third International Congress of Radiology (unpublished). 